\title{
JOÃO VICENTE MARTINS: DO PESSOAL ÀS DISCUSSÕES SOBRE AS NACIONALIDADES ${ }^{1}$
}

Wilza Betania dos Santos ${ }^{2}{ }^{3}$

\section{Resumo}

A análise da vida de Martins objetiva a construção de uma história que possa considerar os elementos contraditórios que são constituidores da sua identidade, bem como perceber as diferentes representações possíveis deste português, envolvendo os pontos de vista e o contexto em que o mesmo vivia nas comunidades portuguesas em estudo. É importante perceber que a história da comunidade portuguesa foi composta de histórias individuais que não negam a história coletiva, são histórias que se somam, entrelaçam-se, influenciam-se, pois afinal o individual é que compõe o coletivo.

\section{Palavras-chaves}

Identidades - histórias - portugueses - nacionalidades.

\section{JOÃO VICENTE MARTINS: DEL PERSONAL A LAS DISCUSIONES SOBRE LAS NACIONALIDADES}

\section{Resumen}

El análisis de la vida de Martins pretende construir una historia que pueda considerar los elementos contradictorios que son constituyentes de su identidad, así como percibir las diferentes representaciones posibles de este portugués, teniendo en cuenta los puntos de vista y el contexto en que lo mismo vivió en las comunidades portuguesas en estudio. Es importante darse cuenta de que la historia de la comunidad portuguesa estaba compuesta de historias individuales que no niegan la historia colectiva, son historias que se suman, entrelazan, influencian, porque después de todo el individuo es que comprende el colectivo.

\section{Palabras-llaves}

Identidad - historias - portugueses - nacionalidad.

\footnotetext{
${ }^{1}$ Este artigo faz parte da tese de doutorado em andamento, sob a orientação do professor doutor Jorge Fernandes Alves.

${ }^{2}$ Universidade do Porto - Porto - Portugal.

${ }^{3}$ Doutoranda em História, Faculdade de Letras da Universidade do Porto - Flup. Já atuou como professora e coordenadora da rede pública e municipal no estado de Pernambuco. Atualmente é investigadora no Centro de Estudos da População, Economia e Sociedade - Cepese, Porto, Portugal. E-mail: wilzabetania@hotmail.com.
} 


\section{JOÃO VICENTE MARTINS: FROM PERSONAL TO DISCUSSION OF NATIONALITIES}

\section{Abstract}

The analysis of Martins' life aims the construction of a history that consider the contradictory elements that constitute its identity, as well as perceive his different representations, involving the points of view and the context in which he lived, in the Portuguese community under study. It is important to realize that the history of the Portuguese community is composed of individual stories that do not denny a collective history, they are stories that are added, intertwined and influenced, because after all it is the individual that makes up the collective.

\section{Keywords}

Identity - history - portuguese - nationalities. 
Este sujeito que parte é um sujeito partido, segmentado, não é uma unidade, uma totalidade. Assim como a sua vida é errante e aberta, ele, enquanto sujeito, é também um sujeito aberto, atravessado por diferentes fluxos sociais. Ele não consegue totalizar as experiências que passam por ele mesmo, que o atravessam. Ele é um entroncamento em que diferentes estradas, diferentes séries históricas, vêm encontrar-se e, ao mesmo tempo, vêm separar-se. Ele não é só ponto de partida, nem só ponto de chegada, ele é travessia, transversalidade ${ }^{4}$.

Esta definição de Durval Muniz sobre o imigrante é bem representativa do percurso de vida do médico e homeopata português João Vicente Martins no Brasil. Martins era um integrante atuante na comunidade portuguesa e por onde passou deixou algumas contribuições: no Rio de Janeiro, colaborou com a Sociedade Portuguesa de Beneficência, atuando como homeopata naquela sociedade ${ }^{5}$; em Pernambuco, foi o sócio fundador do Gabinete Português de Leitura em $1850^{6}$; na Bahia, ele sugeriu aos seus conterrâneos que criassem uma Sociedade de Beneficência ${ }^{7}$. Além disso, Martins cooperou para e incentivou a implantação da Instituição das Irmãs da Caridade na Bahia e no Rio de Janeiro. Era um português ativo e trabalhou em prol de sua comunidade. O historiador Jorge Fernandes Alves cita-o no rol daqueles que muito contribuíram para a criação de instituições que beneficiaram a população portuguesa e por ter também ele, em visita a Portugal em 1852, instituído a Associação da Creche de São Vicente de Paulo na cidade do Porto ${ }^{8}$. Em defesa da homeopatia Martins trilhou por caminhos que o encarrilaram às discussões sobre as nacionalidades brasileira e portuguesa, tema esse muito em alta em meados do século dezenove?.

Após a independência, o "ser brasileiro" era lutar pela causa da liberdade, pela monarquia representativa e constitucional; era ser contra as medidas recolonizadoras da Corte, independentemente de ser nascido no Brasil ou em Portuga ${ }^{10}$. Novas formas de pensar a nação emergiram em discursos que renegavam a maternidade da nação portuguesa e, consequentemente, refutavam a existência da fraternidade entre os dois povos. Os discursos eram redefinidos em coadunação com os interesses dos que os propagavam. A polêmica da qual Martins fez parte esteve inserida nessa conjunção e, nela, ele assumiu a função de explicitar e se mostrar como um exemplo do bom, justo e necessário português.

Como alude Ribeiro, com a separação política entre Brasil e Portugal, "ser brasileiro" foi se construindo ${ }^{11}$ (ou redefinindo). $\mathrm{O}$ “'ser brasileiro' ou 'ser português' (...) envolvia a Nação enquanto

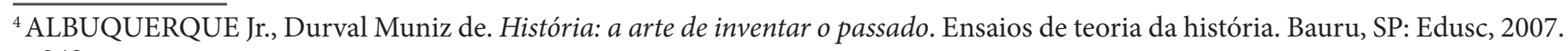
p. 248.

${ }^{5}$ Em março de 1850, foi criada uma enfermaria homeopática pela Sociedade Portuguesa de Beneficência. Entregue pelo sr. Hermenegildo Antônio Pinto, presidente, ao sócio benemérito João Vicente Martins, a tal enfermaria visava atender somente os sócios de nacionalidade portuguesa comprovada e isto gerou alguns questionamentos.

${ }^{6}$ SANTOS, Wilza Betania dos. Gabinete Português de Leitura de Pernambuco: (re)significação duma identidade portuguesa. 123 p. Dissertação (Mestrado), História Contemporânea, Faculdade de Letras da Universidade do Porto, Flup, Porto, Portugal, 2013.

${ }^{7}$ Em viagem de regresso de Pernambuco para o Rio de Janeiro em 1850, Martins desembarcou na Bahia e lá, nas poucas horas de que podia dispor, recebeu de alguns amigos a promessa solene de que no mais curto espaço de tempo seria ali estabelecida uma sociedade portuguesa de beneficência e que esta adotaria os estatutos da Sociedade Portuguesa de Beneficência do Rio de Janeiro. Esta sociedade, no entanto, só se formou em 1857.

${ }^{8}$ ALVES, Jorge Fernandes. Os "brasileiros": emigração e retorno no Porto oitocentista. Porto: Universidade do Porto,1993, p. 382.

${ }^{9}$ Ibidem.

${ }^{10}$ RIBEIRO, Gladys Sabina. A liberdade em construção: identidade nacional e conflito antilusitano no Primeiro Reinado. Rio de Janeiro: Editora Relume Dumará e Faperj, 2002. p. 46. A autora analisou, no primeiro capítulo deste livro, o processo de elaboração de uma "certa identidade nacional" nos primeiros anos do Império e descreveu o que era "ser brasileiro" em oposição ao "ser português" enquanto conceitos politicamente construídos, no âmbito da Corte bem como na esfera da diplomacia. Sobressai em sua análise o estrangeiro, nesse caso o português, como um inimigo natural, a quem se devia vigiar e controlar através de uma série de normas e leis. Apresenta também a definição do português como brasileiro “adotivo", quando este por juramento fidelizava-se à causa brasileira.

${ }^{11} \mathrm{O}$ termo brasileiro possuía um significado singular para os portugueses. Alexandre Herculano, na década de 1870, explicou que o brasileiro em Portugal remetia à ideia de um indivíduo que vivia em melhor condição socioeconômica e não tinha nascido no Brasil, mas que, partindo para lá na infância ou na mocidade "mais ou menos pobre", alcançou algum sucesso e retornou anos depois, "mais ou menos rico". Para ele o termo brasileiro remetia ao sucesso do mineiro do século XVIII. Assim, concluía ser verdadeiro o asserto: "a nossa melhor colonia é o Brasil, depois que deixou de ser colonia nossa”. HERCULANO, Alexandre. Opúsculo. A emigração. 18731875,1876 . tomo IV, p. 112. Dessa forma, a designação "brasileiro" se relacionava com a história da emigração portuguesa para o Brasil e seu uso fazia parte da figura mitológica do emigrante que regressava com sucesso econômico. No imaginário da sociedade portuguesa, a etapa final do trajeto emigratório idealizado era somente alcançada por esses brasileiros, conhecidos também como torna viagem. Esses, por conseguirem realizar uma boa ou razoável poupança no Brasil, adquiriam status e respeito no seu retorno. SANTOS, Wilza Betania dos, 2013, Op. Cit., p. 16. 
'Pátria'/país/região e enquanto indivíduo, digno ou não da 'Pátria', compartilhando ou não com ela os seus interesses e os seus anseios de liberdade" 12 . Ribeiro, ao analisar o antilusitanismo no Primeiro Reinado, chamou a atenção para a ascensão das rivalidades nacionais e raciais, as quais se intensificaram e já não eram amenizadas pelo discurso de laços de "irmandade", desembocando em conflitos de toda ordem e acentuando as diferenças entre brasileiros e portugueses. No processo de formação identitária da nação brasileira as rivalidades nacionais e até raciais eclodiram, e a busca por um espaço para vivenciar a liberdade gerou xenofobias e conflitos sociais. As agitações tinham como causa primaz o mercado de trabalho e a luta pela sobrevivência. Ao se debruçar sobre as manifestações antilusitanas no Rio de Janeiro, Ribeiro concluiu que a identidade nacional foi sendo elaborada nos anos iniciais do Império, quando foi definido o que era "ser brasileiro" em oposição ao "ser português"13.

A reflexão sobre o português não mais como o ex-colonizador, mas como o imigrante que buscava seu lugar na sociedade brasileira, apareceu mesclada pelos chavões pejorativos. Para Robert Rowland, os estereótipos representavam a dificuldade de se definir uma identidade nacional num país multirracial e cuja economia, até finais do século XIX, estava baseada na escravatura com uma forte presença portuguesa no setor comercial ${ }^{14}$. Jeffrey Lesser observou que o preconceito e os estereótipos derivados das tensões sociais apresentavam-se como uma das maneiras pelas quais a identidade do imigrante era contestada, "à medida que na negociação as posições iam sendo expostas e, em seguida, revistas, de acordo com a reação dos diferentes públicos" ${ }^{15}$. A fala de Martins segue a lógica de uma negociação, os argumentos que usava foram importantes para o processo de reformulação de uma identidade portuguesa no Brasil, a qual se deu em meio a uma "guerra verbal", até porque

as construções das identidades não são processos que se desenrolem no isolamento de um espaço determinado e separado do acontecido em outros locais. Assentam também na imitação e na interacção e no confronto com os outros, às vezes pela guerra propriamente dita, outras pela guerra verbal, pelo insulto ${ }^{16}$.

Eu diria que no caso estudado, e referindo-se a presença do português no Brasil, mais do que uma construção de identidade tratava-se de uma reconstrução dos discursos sobre as identidades. Visto ser o português ali identificado como colono/explorador, logo essa reformulação era necessária para (re) significar a sua identidade, num Brasil independente e sem "espaço" para o ex-colono/explorador ${ }^{17}$.

João Vicente Martins tomou como base de defesa o discurso da irmandade. Retornando ao passado comum entre ambos os povos, ele fez uso do mesmo como uma espécie de arma de defesa contra as acusações que sofria, imputações estas que se estendiam para a presença portuguesa no Brasil. O presente artigo busca narrar uma das muitas histórias da vida deste médico português no Brasil, por meio de uma abordagem que considera que os elementos contraditórios também são constituidores de uma identidade. Compreendem-se através deste imigrante português, algumas das diferentes representações do "ser português" no contexto estudado, visto ser ele entendido como "um entroncamento em que diferentes estradas, diferentes séries históricas, vêm encontrar-se"18.

\footnotetext{
${ }^{12}$ RIBEIRO, Gladys Sabina, 2002, Op. Cit., p. 48.

${ }^{13}$ Ibidem, p. 21.

${ }^{14}$ ROWLAND, Robert. Manuéis e Joaquins: a cultura brasileira e os portugueses. Etnográfica, vol. V, n. 1, p. $157-172,2001$.

${ }^{15}$ LESSER, Jeffrey. A negociação da identidade nacional: imigrantes, minorias e a luta pela etnicidade no Brasil. São Paulo: Unesp, 2001. p. 23.

${ }^{16}$ SOBRAL, José Manuel. Identidades e narrativas no tempo do Império. In: SOBRAL, José Manuel. Portugal, portugueses: uma identidade nacional. Lisboa: Fundação Francisco Manuel dos Santos e José Manuel Sobral, 2016 [e-book]. p. 6 de 13.

${ }^{17}$ SANTOS, Wilza Betania dos, 2013, Op. Cit.

${ }^{18}$ ALBUQUERQUE Jr., 2007, Op. Cit., p. 248.
} 


\section{Reafirmações de nacionalidades}

Pois se eu sou Portuguez, queres tu por ventura que eu me assigne Grego ou Turco? Miserável! ... (...) Sou portuguez, e hei de morrer portuguez! Sou portuguez que honrei sempre o Brasil, e sempre tenho respeitado a nacionalidade brasileira ${ }^{19}$.

Confrontado por sua postura de patriotismo português, Martins assumiu-se português e se fez reconhecer português numa nação em formação. Não podia/queria negar a sua nação/ pátria, (definida como o local em que nascera), pois nascer português consequentemente o faria morrer português. Ao mesmo tempo em que ratificou que pertencer a sua pátria não desmerecia a nacionalidade brasileira, visto que "Nenhum estrangeiro terá sido mais bem reconhecido que eu neste país: nenhum será mais grato" ${ }^{20}$. Como salienta Sobral a nossa identidade pessoal é "inevitavelmente nacional, por ser marcada de pertença coletiva" 21 , logo, pertencer a nação de origem, "ser português", foi assumido como uma identidade pessoal que o definiu e o enquadrou como um integrante da colônia portuguesa no Brasil.

Viviam-se tempos de agitadas discussões sobre a questão das nacionalidades, qualquer atitude que violasse a lei em voga era considerada como sinal de desrespeito a nação e taxada como uma postura de "antinacionalismo". O nacionalismo, entendido como "sentimentos e comportamentos particularistas, de afecto, defesa e exaltação do que é próprio, da sua autonomia e dos seus interesses" 22 , acompanhava a emergência das identidades nacionais naquele momento. Portugal havia perdido o seu domínio sobre o Brasil, afetando diretamente o status do ex-colono português que residia na nova nação. Identidades lusitanas eram refeitas em diferenciação com o "outro", com o "nacional" e, tomando como base elementos constituidores e/ou demarcadores de uma nacionalidade brasileira, fazia-se uso do discurso de "uma fraternidade pressuposta e que dissolvia a especificidade da imigração: apagava serem os portugueses imigrantes de fato" 23 .

O posicionamento de Martins seguiu uma lógica que enfatizava para a sociedade brasileira que o passado dos portugueses era o seu atual presente. E este presente fazia-se necessário, pois o passado português mostrava aos brasileiros que estes "dever $[i] a[\mathrm{~m}]$ a sua grandeza mais que muito a sua origem, ao sangue português que nas suas veias corre" 24 .

A discussão que Martins trazia à tona considerava que o fator étnico era definidor da grandeza de uma nação, logo, a presença portuguesa era a causa maior da grandeza da nação brasileira. É interessante perceber o jogo de ideias que Martins articula ao falar sobre o Brasil, porque ele usa a definição étnica para expressar não aquilo que Ernest Renan contestou em 1882, ao afirmar que a "consideração étnica não foi de qualquer importância para as nações modernas" ${ }^{25}$, uma vez ser provado a inexistência de uma "raça pura". Martins não defendia abertamente em seus discursos a superioridade dos portugueses, mas fazia crer que este era um grande e importante povo para a formação da nação brasileira. A articulação de Martins tomou um viés diferente, ele usou a justificação étnica não para afirmar a grandeza da sua nação perante os outros povos, mas para justificar os resultados da conquista de sua nação. Vê-se nesse caso que o seu discurso era permeado de fronteiras identitárias, ficando bem delimitado que o povo português deu origem ao povo brasileiro, apesar das diferenças entre o "ser

\footnotetext{
${ }^{19}$ MARTINS, João Vicente. Publicações a pedido. Questões de nacionalidade contra a homeopatia. Jornal do Commercio, Rio de Janeiro, n. 119, p. 2, 29 de abril de 1848, ano XXIII.

${ }^{20}$ MARTINS, João Vicente. (sem título). Rio de Janeiro: Jornal do Commercio, Rio de Janeiro, na 104, p. 3-19, 20 e 21 de abril de 1840, ano 15. Idem. Homeophatia. O cirurgião português João Vicente Martins ao público. Jornal do Commercio, Rio de Janeiro, $\mathrm{n}^{\circ}$ 47, $\mathrm{p}$. $1-2,16$ de fevereiro de 1846, ano XXI.

${ }^{21}$ SOBRAL, José Manuel, Op. Cit., 2016, p. 3 de 9.

${ }^{22}$ Ibidem, p. 7 de 9.

${ }^{23}$ RIBEIRO, Gladys Sabina; TERRA, Paulo Cruz;_POPINIGIS, Fabiane. Portugueses e cidadãos. Experiências e identidades nos séculos XIX e XX. Rio de Janeiro: Mauad X; Faperj, 2018. p. 9.

${ }^{24}$ MARTINS, João Vicente. Homeopatia - O cirurgião português João Vicente Martins ao público. Jornal do Commercio. Rio de Janeiro, $n^{\circ} 47$, p. 2, 16 de fevereiro de 1846 (Grifos meus).

${ }^{25}$ RENAN, Ernest. Que é uma nação? Tradução de Samuel Titãn Jr. Revista Plural. São Paulo, Sociologia, USP, vol. 4, n. 154-175, p. $166,1^{\circ}$ semestre 1997. 
brasileiro" e o "ser português".

O caminho que João Vicente Martins decidiu seguir o fez enveredar por discussões que desencadearam debates calorosos e cheios de acusações, em que o principal teor se pautou em questões das nacionalidades. As imputações sofridas por ele eram advindas dos vários médicos alopatas e outros tantos nacionalistas, e isto o levou a se autoapresentar à sociedade, no intuito de responder às acusações que vinha sofrendo na imprensa, a qual o definia como um violador das leis brasileiras. Estas imputações tornaram-se recorrentes e, para retificar as versões que circulavam sobre si, ele decidiu fazer um resumo de sua própria vida e apresentá-lo na imprensa. Faço a partir de então uma breve síntese do mesmo para melhor esclarecer os fatos.

João Vicente Martins nasceu em 1808 em Lisboa, era filho de Matheus Martins, formou-se médicocirurgião na Escola de Cirurgia de Lisboa. Chegou a capital do Brasil em 30 de janeiro de 1837 (a bordo do brigue Formosura ${ }^{26}$ onde se casou com uma brasileira, d. Carolina Rosa dos Santos Martins, com quem adotou alguns filhos.

Martins foi discípulo de José Lourenço da Luz, um reconhecido cirurgião português de oftalmologia em Portugal ${ }^{27}$. Ao chegar ao Brasil, ele atuou como alopata na especialidade das "moléstias dos olhos"28. Por ser bem acolhido ficou convencido, naquele momento, de que tinha bons amigos e exerceu a sua profissão sem nenhum obstáculo. Por todos os estabelecimentos por que passou nenhuma crítica sofreu até que resolveu abandonar os empregos e decidiu somente se dedicar a cirurgia dos olhos, pois via nela algo positivo para a arte de curar. Logo após ter tomado esta decisão, resolveu se aventurar em uma peregrinação pelos sertões de Minas e da Bahia, pois o seu desejo de ensinar e dividir conhecimentos era muito forte, e "até [com] seus detratores" ele quis dividir os saberes. Foram esses momentos em que esteve muito feliz, pois, onde chegou, foi aceito com a "generosidade propriamente brasileira, com essa cordialidade que é para a maneira selvagem por que hoje sou tratado o mesmo que a luz é para as trevas (...)"29. E por ser bem estimado ele teve força para seguir por outros lugares em que fez alguns amigos e irmãos. Ao chegar à Bahia foi convidado por "distintos lentes" da Faculdade de Medicina para praticar algumas operações e, devido o sucesso obtido, muitos pacientes saíram da Bahia e foram ao Rio de Janeiro para serem operados por ele. Após três anos voltou para o Rio de Janeiro e quis indagar a verdade e "encontrar essa ciência porque debalde esperado havia, e eu tinha recebido fatal desengano (...) e dirigi-me a Dr. Mure"30. E, foi através de Benoît Mure, homeopata francês, que Martins entregou-se à causa da homeopatia, sendo considerado o braço direito de Mure no Brasil, vindo a ser seu substituto quando o mesmo partiu para a França em 1848. Ambos desenvolveram uma amizade que foi reproduzida numa dedicatória transmitida na primeira edição do livro de Mure, Patogenesia brasileira, publicado em Paris em 1849:

\footnotetext{
${ }^{26}$ MARTINS, João Vicente. (sem título). Jornal do Commercio, Rio de Janeiro, no 104, p. 3, 19, 20 e 21 de abril de 1840, ano 15; Idem. Homeophatia. O cirurgião português João Vicente Martins ao público. Jornal do Commercio, Rio de Janeiro, n. 47, p. 1-2, 16 de fevereiro de 1846, ano XXI.

${ }^{27}$ MARTINS, João Vicente. Correspondência. Jornal do Commercio, Rio de Janeiro, n. 225, p. 3, 25 de setembro de 1839. GALHARDO, José Emígdio Rodrigues. Livro do $1^{\circ}$ Congresso Brasileiro de Homeopatia. Rio de Janeiro: Instituto Hahnemanniano do Brasil, 1928. p. 303.

${ }^{28}$ Logo ao chegar à capital do Império, Martins atuou como cirurgião dos olhos. Jornal do Commercio, Rio de Janeiro, n. 28 , p. 3,6 de fevereiro de 1837.

${ }^{29}$ MARTINS, João Vicente. Homeopatia - O cirurgião português João Vicente Martins ao público. Jornal do Commercio, Rio de Janeiro, n. 47, p. 2, 13-16 de fevereiro de 1846, ano XXI.

${ }^{30}$ FOLHINHA HOMEOPÁTICA do Brasil para o ano de 1846, sexagésimo segundo da verdadeira medicina. Niterói: Tipografia Niteroyense de MG de S. Rejo, 1845. p. 2. Benoît Mure ou Bento Mure, como foi chamado no Brasil, ou mais propriamente BenoîtJules Mure nasceu no dia 4 de maio de 1809, em Lyon, França, e faleceu a 4 de março de 1858 no Cairo, Egito. Após tratamento feito de uma tuberculose pela homeopatia, resolveu propagá-la, iniciando para isto seus estudos de Medicina na Escola de Montpellier. Foi um importante personagem na história da medicina brasileira especialmente no contexto da homeopatia. Deixou influências e as repercussões de seu trabalho continuam. Mure chegou ao país depois de realizar uma peregrinação na Europa, aonde difundiu e divulgou os princípios da então nova arte médica. Palermo (na Sicília), Paris, Cairo e Malta estiveram em seu roteiro de propaganda homeopática. Quando desembarcou no Rio de Janeiro a bordo da barca francesa Eole em novembro de 1840, Mure estava com 31 anos de idade e repleto de projetos visionários. Permaneceu no Brasil de 1840 a 1848 (entre 21 de novembro de 1840 e 13 abril de 1848 ). Era filho de um rico burguês de Lyon. Disponível em: http://homeoint.org/articles/portugues/mure.htm. Acesso em: 29 jun. 2017.
} 
Oh meu amigo! Este é o papel que lhe foi destinado no grande drama da introdução da homeopatia no Brasil.

(...) Vinte vezes, quando fadigado pela luta, com o meu braço tornando-se mais pesado, quando minha vista perturbada só via inimigos ao meu redor, eu senti este gládio invencível restabelecer as probabilidades do combate. Nas questões de doutrina, na pressão dos interesses privados sobre o banco do réu, eu via brilhar um rápido relâmpago e o braço de João Vicente Martins abater meus adversários ${ }^{31}$.

Este encontro com a verdadeira arte de curar fez Martins seguir seu "destino" e, assim, decidiu retornar para a Bahia com o intuito de ali divulgar a homeopatia. E foi a partir dessa mudança do rumo que quis dar a própria carreira que muitos se declararam seus inimigos e, inclusive, alguns daqueles que anteriormente o receberam com ternura. Martins declarou que foi a partir daquele momento que eles passaram a contestar todas as suas habilitações, quer as conferidas pela escola, quer as adquiridas pelos empregos que ocupou no Brasil ${ }^{32}$.

Martins acreditava que a "guerra" que lhe era imposta apenas expressava a falta de amor de seus acusadores para com a miséria humana e argumentava que intentavam impedir o seu trabalho por ser uma ameaça à hegemonia da ciência (medicina alopata), partilhada apenas entre uma classe de homens. Visto que a homeopatia melhorava a saúde pública e por não ser a saúde e sim a enfermidade o que sustentava os tais médicos, ele compreendia o motivo pelo qual estava a sofrer tal perseguição ${ }^{33}$. Para fazer frente às acusações que sofria, Martins, além de narrar todo o seu percurso desde que chegara ao Brasil, também fez questão de relatar que nunca foi pesado aos brasileiros, pelo contrário, disse ele:

Se como o vosso pão, senhores, é o pão que, afadigado, tenho a custa do meu trabalho; se recebo a vossa generosa hospitalidade, vo-la retribuo com serviços que, não vós, mas vossos filhos hão de saber levar-me em conta.

A mesquinhez com que alguém fala sempre, e em todas as questões, de nacionalidade e destas praias hospitaleiras, não pode ter significação alguma genérica; se a tivesse, que se diria de um povo que assim pensa, e que não tarda em mostrar-se grande, e que devera a sua grandeza mais que muito a sua origem, ao sangue português que nas suas veias corre? $?^{34}$ (grifos meus).

Três coisas foram ressaltadas nesse discurso e volta e meia elas reapareceram noutras exposições e em situações diferentes. Primeiramente, ele fez questão de pontuar que o que ganhava era fruto do seu trabalho; segundo, lembrava que a hospitalidade recebida no Brasil era retribuída com os serviços que prestava, os quais seriam ainda mais sentidos pela geração vindoura; e, por fim, afirmou que a grandeza dos nacionais era herança de sua nação e um povo grande, como era o povo que tinha o sangue português nas veias, se destacava e por isso não deveria ser desprezado. Ao fazer uso desses argumentos ele tocou no ponto nevrálgico de um dos assuntos mais fortes nas pautas de discussões da época: o nacionalismo. E mais do que isso, associou-se ao mesmo, pois sendo ele português, desprezálo era também desconsiderar a grandeza da nação portuguesa, uma vez que o sangue que corria nas suas veias representava a grandeza daquela nação, a qual estava na gênese da nação brasileira. A vida de Martins foi, através de seu discurso, se entrecruzando com a questão da formação nacional. E apesar das discussões inicialmente partirem da credibilidade da medicina homeopática, quase sempre se desencadearam noutras discussões ligadas a questão da nacionalidade. Logo, alguns assuntos muitas vezes de cunho pessoal se transformavam em gerais e vice-versa.

Como um indivíduo influenciado pelo contexto, a ideia do nacionalismo referida por Martins

\footnotetext{
${ }^{31}$ MURE, Benoît-Jules. Dedicatória a João Vicente Martins in Patogenesia brasileira e doutrina da escola do Rio de Janeiro. Paris, 1849. Revista Brasileira de Homeopatia, vol. 1, n. 1, p. 12-13, 1991.

${ }^{32}$ MARTINS, João Vicente. Jornal do Commercio, 1846, Op. Cit., p. 2.

${ }^{33}$ Apesar de Martins atribuir tal perseguição a sua adesão a homeopatia, ele foi condenado em 1848 por não ter legalizado os seus títulos como cirurgião pela Escola de Medicina e Cirurgia de Lisboa, mas não foi impedido de atuar na qualidade de professor de Homeopatia. Foi condenado e apelou da sentença, cuja razão publicou no Jornal do Commercio de 24 de junho de 1848 , porém a sentença foi confirmada e ele foi obrigado a pagar uma multa de $10 \$ 000$ por ter sido cirurgião do Imperial Hospital dos Lázaros da Corte por oito anos.

${ }^{34}$ MARTINS, João Vicente, 1846, Op. Cit., p. 2. 
estava atrelada a questão da origem e baseava-se na influência de um povo sobre o outro. Afirmava que a grandeza da nacionalidade brasileira devia muito ao sangue português, o mesmo sangue que lhe corria nas veias. Além disso, foi defensor de que o valor e o sentimento cristão, específicos da cultura ocidental, estabeleciam a real importância do ser humano e eram elementos identificadores das nações, juntamente com a língua (imposta ${ }^{35}$ ) e a origem. O povo português era o principal responsável pela grandeza e estabelecimento da nova nação, mas ele não era a nação brasileira. Há, de certa forma, um deslocamento na definição entre ser português e ser brasileiro, bem como uma aproximação entre o ser brasileiro e o ser português; uma dualidade discursiva que justificava a herança brasileira adquirida da nação portuguesa.

Os questionamentos da distribuição do poder e dos benefícios concedidos a alguns eram parte do contexto das querelas entre Martins e alguns nacionalistas, portanto a colocação de Martins representava certo tipo de poder na sociedade em que vivia. Sua posição o fez galgar espaço nos meios de comunicação, uma rede que ele bem soube utilizar e empregar. Como diz Foucault ${ }^{36}$, para transmitir a informação "a través de la lengua, de um sistema de signos o de cualquier outro medio simbólico. Comunicar sempre es, sin lugar a dudas, un determinada manera de actuar sobre el otro o los otros" $^{37}$.

\section{Espontaneidades: também para "vir a ser útil a [sua] pátria..."}

João Vicente Martins fez uso da linguagem escrita através da imprensa para expressar suas ideias. Em 1849, ele solicitou um espaço para contribuir com a publicação de artigos no jornal Correio Mercantil do Rio de Janeiro. Atendido, iniciou uma série sob o título "Espontaneidades".

Antes de iniciar esta série de artigos, porém, ele fez uso do discurso de um médico alopata convertido a homeopatia, o dr. Alexandre Mello de Moraes, para fortalecer suas asseverações: - "Sr. Redator do Correio Mercantil. Muita gente há que não pode sofrer que a igualem, e muito menos que a excedam. Não sou eu dessa gente: abraço os que me igualam, admiro e venero os que me excedem" 38 .

Testemunhou então a conversão do dr. Mello de Moraes na Bahia, pois lá ele tinha sido o seu adversário "mais decidido e o melhor aparelhado para o combate" ocorrido entre ele e os médicos alopatas. Todavia, dr. Mello foi estudar a homeopatia para ter argumentos contra ela e, nessa busca, foi convencido pela nova ciência médica, converteu-se a causa da mesma e se transformou num exemplo legitimador dos benefícios oriundos da homeopatia. Martins então transcreveu um artigo redigido pelo dr. Mello Moraes a narrar a sua própria conversão e o tornou um testemunho vivo e prova legitimadora das suas convicções na causa homeopática.

Em abril de 1849, Martins iniciou a publicação da série intitulada “Espontaneidades”. Neste espaço, ele disse que se dedicaria a publicar aquilo que surgisse em seus pensamentos nas horas vagas, que reconhecia que nem sempre a sua reflexão agradaria a todos e que apesar de não seguir um método ou uma ordem de temas, seguiria a determinação de "ser útil ao Brasil por amor dos portugueses e útil a Portugal por amor dos brasileiros" 39 . Desejava, portanto, que os leitores percebessem que assim como ambas as nações eram irmãs, deveriam elas estreitar sem reservas "os laços de sangue, de linguagem, de religião, de pensamentos, de inclinações, de interesses familiares que as unem” ${ }^{40}$. Disse ainda que a produção de sua escrita seria espontânea, daí o título ser Espontaneidades, mas que, apesar disso,

\footnotetext{
35 Patrick Gary, em entrevista publicada em https:/www.publico.pt/2008/12/05/culturaipsilon/noticia/e-assim-nasceu-onacionalismo-etnico-217960, respondeu ao seu arguente a seguinte questão: "No livro fala na importância da língua e da filologia para criar as nacionalidades europeias. Em Portugal, costumamos dizer que a nossa pátria é a nossa língua. [Resposta:] Que português? Foi esse também o grande empreendimento do século XIX: as línguas oficiais, criadas e depois impostas através da escola pública. E depois dizemos que é a nossa língua. Há casos de absoluta invenção. O irlandês criado no século XIX, que hoje é aceite como irlandês, nunca foi falado em parte nenhuma. É artificial. Como o hebreu. O mesmo se pode dizer, mesmo que em menor escala, para muitas línguas nacionais. Pode dizer-se 'nós somos a nossa língua' depois de terem obrigado toda a gente a falá-la".

36 FOUCAULT, Michel. Cómo se ejerce el poder. Disponível em http://www.unizar.es/deproyecto/programas/docusocjur/ FoucaultPoder.pdf. O artigo original em francês foi publicado em DREYFUS, Hubert; RABINOW, Paul; FOUCAULT, Michel. Un parcours philosophique. Paris: Editions Gallimard, 1984.

${ }^{37}$ Ibidem, p. 1.

${ }^{38}$ Correio Mercantil, Rio de Janeiro, n. 107, p. 3, 20 de abril de 1849.

${ }^{39}$ MARTINS, João Vicente. Publicações a pedido. Spontaneidades. Correio Mercantil, Rio de Janeiro, n. 110, p. 2, 23 de abril de 1849. ${ }^{40}$ Idem. 
seguiria o que acreditava, pois era acostumado ao trabalho e detestava o ócio, por isso dedicaria as horas vagas a sociedade portuguesa no novo mundo, "mas não sem reciprocidade, porque há de ser ela em proveito de minha pátria também”. Por fim, deixava registrado que talvez não respondesse aos anônimos que o criticassem, visto que tudo que defendia era muito claro e nada fazia às escondidas ${ }^{41}$.

A partir desse artigo, Martins deu início a uma série de discussões que nada tinham a ver com a homeopatia e abriu um debate em que demonstrou uma preocupação com a (re)construção dos discursos que (re)significassem a identidade portuguesa como sinônimo e expressão do amor por Portugal e por todos os portugueses, pois este amor, apesar de não se ter acabado, muitas vezes "anuviou", por culpa não se sabe de quem. Diante disso, acreditava ainda em sua "desgraça vir a ser útil a [sua] pátria..., reconquistando para ela o amor de seus irmãos de aquém-mar" ${ }^{42}$. Martins passou a fazer uma análise dos laços de sangue que uniam portugueses e brasileiros por trezentos anos, laços tão fortes que desejava que nem mesmo a espada de outro Alexandre fosse capaz de desatar um do outro. Ele viu o intricar de uma relação nitidamente e inegavelmente diferenciada em um fato: os filhos de portugueses nascidos no Brasil eram naturalmente brasileiros, já os de outros estrangeiros eram naturalmente estrangeiros. Para que os primeiros viessem a ser brasileiros tinham que ter a autorização dos pais e, quando adultos, confirmariam se o queriam ser; já os segundos não careciam da autorização para ser brasileiros; logo, os "laços de sangue" uniam os dois povos ${ }^{43}$.

Assim como Varnhagen ${ }^{44}$ (1816-78), seu contemporâneo, Martins não visualizava aspectos negativos na relação entre portugueses e brasileiros, pelo contrário, acreditava que os brasileiros nunca se esqueceriam dos benefícios de um passado adquiridos através de Portugal. O historiador José Carlos Reis definiu bem essa concepção:

Sobre a guerra da independência, Varnhagen não a vê como uma verdadeira guerra. Para ele, o Brasil não se esquecerá jamais do seu tutor de infância, e Portugal não esquecerá jamais dos socorros que o Brasil lhe prestou. Nenhum deles é devedor do outro. Ambos devem gratidão e louvores um ao outro. Se a metrópole agiu, às vezes, com despotismo, injustiça, incoerência, ignorância e governou mal, não se deve condená-la, pois ela quis acertar sempre. Não era o governo central que errava, mas os governos locais com sua excessiva liberdade, verdadeiros senhores feudais. A metrópole agiu com rigor contra homens que se levantaram contra ela e, se foi muito rigorosa, as razões do Estado justificam ${ }^{45}$.

E o que falar dos laços de linguagem? A língua portuguesa era a falada pelas cidades e povoações mais notáveis do Brasil. O falar a mesma língua também definia os laços e a unidade entre brasileiros e portugueses, defendia Martins.

Conforme salienta o historiador Erick Hobsbawm, um dos critérios definidores de uma nação no século dezenove era a "existência de uma elite cultural longamente estabelecida, que possuísse um vernáculo administrativo e literário escrito" ${ }^{46}$. Assim, a identificação nacional era fortemente linguística, fato este bem explorado em Varnhagen na sua composição da História geral do Brasil, em que transformou a narrativa da colonização brasileira num elogio à colonização portuguesa, fazendo o uso de depoimentos como o de José Bonifácio d’Andrada e Silva, o qual definiu a língua portuguesa como sendo "bela, rica e sonora; menos dura e tarda que a alemã e a inglesa; mais energética e variada

\footnotetext{
${ }^{41}$ Idem.

${ }^{42}$ MARTINS, João Vicente. Publicações a pedido. Spontaneidades I. Correio Mercantil, Rio de Janeiro, n. 114, p. 3, 27 de abril de 1849.

${ }^{43}$ Ibidem.

${ }^{44}$ Francisco Adolfo Varnhagen (1816-1878), filho de oficial alemão, engenheiro metalúrgico que trabalhara no Brasil e de uma portuguesa. Residiu em Portugal desde os seis anos de idade e morou pouco tempo no Brasil. Sua formação em Lisboa foi mais militar, técnica e matemática. Porém, estudou paleografia, diplomática e economia política. Gostava de frequentar arquivos públicos (uma novidade do século XIX) por onde passava. Considerado o "Heródoto brasileiro", portanto, o fundador da história do Brasil, mesmo que já existissem outros escritos sobre o Brasil antes dele, tais como os de Pero de Magalhães Gandavo (História da província de Santa Cruz, 1576), de frei Vicente Salvador (História do Brasil, 1627), Robert South (História do Brasil, 1810), este último, apesar de nunca ter estado no Brasil, disputa com Varnhagen o título. REIS, José Carlos. As identidades do Brasil 1: de Varnhagen a FHC. Rio de Janeiro: Editora FGV, 2017.

${ }^{45}$ REIS, José Carlos. Op. Cit.

${ }^{46}$ HOBSBAWM, Eric J. Nações e nacionalismo desde 1780: programa, mito e realidade. Rio de Janeiro: Paz e Terra, 1990 artigos. p. 49.
} 
ao ouvido que a italiana, mais suave e natural que a castelhana e superior em tudo à francesa" ${ }^{47}$. Martins seguia essa tendência de pensamento, em que exaltar a língua portuguesa significava igualmente "exaltar o Brasil e afirmar a sua viabilidade como nação" 48 .

Outro aspecto definidor eram os "laços de religião" que eram, dentre todos os outros, aqueles impossíveis de não serem lembrados.

...quando possível fosse que alguém se esquecesse de que o mesmo sangue gira nas veias de uns e de outros; quando por longa ausência de suas respectivas pátrias... esquecidos de seu pátrio idioma ... faria um deles o sinal da cruz, e tinha logo nas lágrimas do seu contrário sobejo refrigério a sede ${ }^{49}$.

Num outro artigo, "Spontaneidades III"50, Martins retomou a mesma ideia e lembrou que, em qualquer lugar que viesse a se encontrar um português e um brasileiro, logo se reconheceriam por pertencerem a mesma família, falarem a mesma linguagem e por serem unidos numa só religião. E, conquanto fossem nações distintas, o "velho Portugal" e o "nascente Brasil" tinham escrito em seus corações a palavra monarquia e, apesar de diferenciadas, eram como duas províncias de um mesmo Império. Martins, dessa forma, exalta a unidade herdada da monarquia e a missão católica de civilização, sacralizando, portanto, seu discurso, o qual teoricamente não poderia ser contradito.

Sobressaiu-se aqui uma preocupação que foi típica do Instituto Histórico e Geográfico Brasileiro (IHGB). Este instituto foi criado em 1838 e exerceu grande influência na construção de uma história em que o Brasil era pensado como nação, ao mesmo tempo em que se elogiava a colonização portuguesa. O Brasil não deveria ser compreendido como continuidade de Portugal e o enaltecimento à presença portuguesa no Brasil deveria ser extensivo a nova nação brasileira. Nesses moldes, a construção da história nacional seria baseada num passado que orgulhasse a nação e a fizesse seguir em frente e Francisco Adolpho Varnhagem assim o fez em sua escrita sobre a história do Brasil. Emerge das características consideradas pelo IHGB um discurso dual, mas que servia para ratificar que cada país era uma nação em separado, apesar do passado comum.

O discurso persuasivo adotado por Martins o fez enveredar por uma discussão que perdurou por longo tempo. Defendeu ele que ambas as nações se deveriam unir contra o inimigo em comum que era o governo inglês. Ou seja, não havia motivos para os portugueses e os brasileiros se autocombaterem, pelo contrário, unidos e fortalecidos em aliança contra o inimigo em comum, ambos alcançariam a felicidade. Martins alimentava a ideia de que o passado da nação brasileira recém-independente era um passado do qual ela poderia se orgulhar. $\mathrm{O}$ povo brasileiro deveria fiar-se nesse passado, unir-se a ele e seguir com confiança rumo ao seu futuro.

A ideia de um passado histórico era um dos critérios para que um povo fosse considerado nação no século XIX, como afirma Hobsbawm: "era sua associação histórica com um Estado existente ou com um Estado de passado recente e razoavelmente durável" ${ }^{51}$. Um passado bem aos moldes da definição de Detienne o qual diz que, apresentado na fórmula ocidental, pode "ter sido e ser o passado naquilo que ele tem dele mesmo e no que tem de outro" 52 .

Uma das coisas que mais irritou Martins foram os acusadores incógnitos, os quais frequentemente não assinavam a própria opinião divulgada pelos artigos e faziam uso de vários pseudônimos: "Um Nacional, O Socialista (conforme Galhardo ${ }^{53}$, esse socialista era o dr. Antonio da Costa), O Amigo da

\footnotetext{
${ }^{47}$ KHALED Jr., Salah H. Horizontes identitários: a construção da narrativa nacional brasileira pela historiografia do século XIX. Porto Alegre: EdiPUCRS, 2010. p 181.

${ }^{48}$ Idem, ibidem.

${ }^{49}$ MARTINS, João Vicente. Publicações a pedido. Spontaneidades I. Correio Mercantil, Rio de Janeiro, n. 114, p. 3, 27 de abril de 1849.

${ }^{50}$ Idem. Correio Mercantil, n. 112, p. 3, 2 de maio de 1849.

${ }^{51}$ HOBSBAWM, Eric J. Op. Cit., p. 49.

${ }^{52}$ DETIENNE, Marcel. A identidade nacional, um enigma. Tradução de Fernando Scheibe. Belo Horizonte: Autêntica Editora, 2013. capítulo IV, p. 4 de 18. [e-book] (Coleção História e Historiografia).

${ }^{53}$ GALHARDO, José Emígdio Rodrigues. Livro do $1^{\circ}$ Congresso Brasileiro de Homeopatia. Rio de Janeiro: Instituto Hahnemanniano do Brasil, 1928. p. 324, 325. No Jornal do Commercio, 14 de fevereiro de 1846, foi o dr. Mure que trouxe à tona que O Socialista era artigos
} 
Verdade, Um Nacional que Não Tem Medo, O Caloiro ${ }^{54}$, Anti-Asmodeu, Um Venerador da Verdade," dentre outros. Por ser contrário a esse posicionamento ele dedicou o tema "Espontaneidade" do dia 22 de maio de 1849 a essa discussão.

\begin{abstract}
Possuir o direito e os meios de apelar para a opinião pública é possuir um grande tesouro, é alcançar uma completa reabilitação, devida somente a própria justiça; independente do auxílio das mesmas leis, sobranceiras a todas as considerações humanas. Mas a liberdade de imprensa, tal qual por todas as nações está hoje admitida, pode ser um grande mal. Com efeito, quando um homem honrado com o rosto descoberto pode dizer tudo quanto pensa, justiça lhe é feita no supremo tribunal da opinião pública; quando porém, um malvado pode dizer tudo o que quer, coberto o rosto com a capa do anônimo, nem será imparcial o juízo da opinião pública, nem o juízo dos magistrados produzirá todo o efeito salutar, ainda mesmo sendo o mais reto (...). A liberdade de imprensa, sendo um grande bem, podia fazer grandes males, e dar causa a torpes imoralidades (...) todo e qualquer escrito devia sempre ser publicado com a assinatura do próprio autor. Os jornais deveriam ser sem cor política e dentre outras coisas deveriam transcrever as notícias dos melhores artigos de jornais portugueses, isso seria nobre além de lucrativo, e estreitaria os laços naturais que ligam a família portuguesa d’Aquém e d’Além mar ${ }^{55}$.
\end{abstract}

A postura de Martins mesmo quando contrariado pelos seus acusadores, seguia na linha da reflexão sobre os "laços naturais" e a valorização da cultura portuguesa. Seus discursos se baseavam sempre na apreciação de sua nação e, mesmo quando discordou em alguns pontos ou assuntos relacionados a sua pátria, ele fez questão de frisar que sua crítica era para o bem e não para o mal dela e, como associava a relação do Brasil com Portugal a uma conexão de parentesco, ressaltava sempre que o bem desejado a um se refletiria no outro. Em 29 de junho de 1849, por exemplo, fez uso da seção "Espontaneidades" para expor um descontentamento sobre uma publicação de um jornal, a qual, em sua opinião, denegria a imagem de Portugal. Referiu-se a um artigo em que foi publicada uma carta particular a acusar o governo de Portugal de deixar passar bandidos e prender pessoas decentes, dentre outras acusações de tirania. Martins se posicionou contra tal publicação, apesar de salientar não ser a favor do governo português. Ao iniciar o artigo citou Camões “...Entre os Portugueses alguns traidores houve algumas vezes", e ao encerrar seus comentários disse: "O Jornal do Commercio devia ter presente sempre que ele subsiste a custa de seus assinantes Portugueses e Brasileiros; e que estes são todos irmãos; e que ofender a um é ofender a outro; e que melhor será viver em paz com todos" ${ }^{36}$.

Sobre sua opinião se manifestou um nacionalista de pseudônimo Anti-Asmodeo, e disse que Asmodeu, no bom português, "era o diabo" e o diabo nunca fez coisa boa, sendo assim o sr. Martins era o sr. Asmodeu e nunca faria coisa boa na "Terra de Santa Cruz". Mas se ele vivesse em Portugal onde existiam muitos Asmodeos, alguns dos quais vieram para o Brasil infectá-lo, Martins com certeza seria aplaudido por sua contestação a carta publicada. Todavia, disse o crítico, ao contrário do que Martins havia falado, nem os portugueses nem os brasileiros se ofenderam com a publicação da carta que se pronunciou sobre as atrocidades do governo lusitano, pois o repúdio exposto na mesma expõe os valores de liberdade que, portanto, diante de explanações como estas muitos tiranos já recuaram. Assim sendo, Martins deveria apenas se preocupar com as vendas dos seus glóbulos homeopáticos para ter a garantia de não ir sofrer em Portugal, como tantos outros, as atitudes daquele governo ${ }^{57}$.

A exposição de Martins nas páginas do Mercantil rendeu ao jornal uma crítica violenta, publicada n'O Grito Nacional, na qual aquele jornal era acusado de ter trocado o belo ideal do princípio da liberdade e da justiça, outrora defendido com eloquência, pela realidade do ouro sedutor nos esboços dos artigos do "contrabandista" e sobre a "espelunca homeopática". O Mercantil "cuspiu o publico com

o dr. Antonio da Costa. No mesmo jornal de 13 de fevereiro de 1846, João Vicente Martins, disse em Homoeopathia - o cirurgião portuguez João Vicente Martins ao publico: “Tendo havido quem desmascarasse O Socialista, tendo havido quem lançasse em rosto ao sr. dr. Antônio da Costa o seu nome próprio...”.

${ }^{54}$ Dr. Mure sugeriu em uma de suas respostas que ao dr. A. da Costa pertenciam também os pseudonymos Leigo, Socialista, Calouro etc. In. Comunicados: Homeopathia. Jornal do Comércio, Rio de Janeiro, n. 78, p. 2-3, 19 de março de 1846, ano XXI.

${ }^{55}$ MARTINS, João Vicente. Espontaneidades VII. Correio Mercantil, Rio de Janeiro, n. 139, p. 3, 22 de maio de 1849, ano VI.

${ }^{56}$ Correio Mercantil, Rio de Janeiro, n. 175, 29 de junho de 1849.

${ }^{57}$ Anti-Asmodeo. Correspondência. Correio Mercantil, Rio de Janeiro, n. 179, p. 3,3 de julho de 1849, ano VI. 
a propaganda do cirurgião português: - renasça o Portugal no Brasil"58.

Acompanhando a mesma ideia O Fuzil criticou Martins, chamando-o de "galego", insolente, atrevido e excitador dos ânimos da nacionalidade, "quando por acaso se diz a respeito da mãe pátria do galego" 59 . Afirmou ainda que "em um país onde houvesse polícia o galego homeopata não se havia de sair tão bem da política como tem saído da homeopatia" 60 . O que resta é esperar a hora certa, dizia O Fuzil, "em que mostraremos ao galego que no Brasil não se deve falar dos Brasileiros com tanto desrespeito á Nacionalidade"61.

As polêmicas não arrefeciam e eram quase permanentemente noticiadas pela imprensa. Numas vezes, devido às questões de medicamentos, e noutras, pela falta de autorização para a sua atuação na medicina. E para fazer frente a ela, mais uma vez Martins expôs os pormenores de sua vida, desde o momento em que desembarcou no Brasil, reafirmando novamente possuir o diploma de cirurgião pela Real Escola de Cirurgia de Lisboa. Sua defesa se deu porque circulava um boato de que ele seria deportado, mexerico este que ele atribuiu aos seus inimigos alopáticos, bem como a alguns "homeopatas impuros", estes últimos misturando a nova ciência com a velha ciência. Apesar de esclarecer ser aquele um falso boato, Martins disse que mesmo que viesse a ser obrigado a deixar o país, para onde ele fosse levaria a verdade homeopática, e que nem por isso deixaria de ser grato "a todos os Brasileiros e a meus patrícios, e aos estrangeiros com quem até agora tenho tido relações"62.

Em março de 1850, foi criada uma enfermaria homeopática pela Sociedade Portuguesa de Beneficência. Entregue pelo sr. Hermenegildo Antônio Pinto, presidente, ao sócio benemérito João Vicente Martins, a enfermaria visava atender somente aos sócios de nacionalidade portuguesa comprovada e, para atestarem a sua nacionalidade, eles precisavam de um documento certificado pelo Consulado português; essa especificação gerou alguns questionamentos.

Quem tem olhos para ver, que veja Quem tem ouvidos para escutar, que escute

"Cesse tudo que a antiga musa canta"

Que a influência mais alta se levanta ${ }^{63}$.

A citação acima iniciava um artigo publicado n'O Grito Nacional de 23 de março de 1850. $\mathrm{O}$ artigo falava sobre a Sociedade Portuguesa de Beneficência do Rio de Janeiro, a qual estava a publicar nos jornais alguns anúncios a afirmarem a sua confiança na generosidade e nos patrióticos sentimentos dos portugueses que moravam na capital do Império para levar adiante a obra de criação de uma enfermaria homeopática, sob o comando de João Vicente Martins, que iria honrar o "NOME portuguez" ${ }^{4}$. A enfermaria seria privativa dos portugueses, dizia o jornal, e sob as ordens do charlatão Martins. Conforme o redator, a convocação aos "cebozos, a essa galegada porca, immunda e suja" 65 se dava justamente quando se estava a completar os trinta anos da Independência, e já se tinha quebrado as "ignominiosas algemas da rançosa, e podre metrópole, da nação mais atrasada, corrompida e imoral da Europa"66. Assim sendo, a invocação ao patriotismo, justamente na capital do Império, era uma grande afronta aos brasileiros, porém, quando o Brasil acordasse, todos os "gallegos" seriam enxovalhados. O redator afirmava que a sua crítica não era em relação à análise do sistema da medicina, mas sim contra a arrogância da sociedade, pois se julgava no "direito de instalar-se, para em seguida

\footnotetext{
58 [Sem autor]. Ao Mercantil. O Grito Nacional, Rio de Janeiro, n. 60, p. 4, 26 de maio de 1849. O jornal O Brasil, vol. XI, n. 1411, p. 4, 25 de maio de 1849, também reproduziu uma crítica ao Mercantil sob o mesmo pretexto.

${ }^{59}$ [Sem autor]. O gallego João Vicente Martins. O Fuzil, Rio de Janeiro, n. 9, p. 3, 4 de julho de 1849.

${ }^{60}$ Idem.

${ }^{61}$ Idem.

${ }^{62}$ MARTINS, João Vicente. Esclarecimentos. Jornal do Commercio, Rio de Janeiro, n. 87, p. 3, 29 de março de 1850.

${ }^{63}$ O REDACTOR. Sociedade Portuguesa de Beneficencia. O Grito Nacional, n. 141, p. 2, 23 de março de 1850.

${ }^{64}$ Idem.

${ }^{65}$ Idem.

${ }^{66}$ Idem.
} 
alistar todos os portugueses invocando os seus patrióticos sentimentos" ${ }^{\prime \prime}$, numa atitude expressiva de estrangeiros presunçosos. Além disso, a instalação de uma enfermaria ao desprezar as "leis em vigor, o Decoro, o Brio", também menosprezava a "Nacionalidade Brasileira". O redator do jornal sugeriu que quatro passos fossem tomados para impedir o vitupério, dois dos quais estavam relacionados com a homeopatia, outro com a verificação da verdadeira finalidade da sociedade, e o último referia-se à necessidade de o governo se empenhar para acabar com a influência "perniciosa, constantemente hostil dos - portugueses -: influência, que nos degrada, avilta, que nos tenta matar"68. Pois, até mesmo alguns saquaremas tinham reconhecido tal miséria da pátria brasileira, um destes tinha procurado o redator e reconhecido que o governo se deixava dominar pela influência portuguesa, e que esta era a causa de todos os "males passados, presentes e futuros" 69.

A temática sobre a nacionalidade e a defesa da grandeza de sua pátria foi recorrente nos discursos de João Vicente Martins, sua luta pelo estabelecimento da medicina homeopática o levou a este caminho. Considerava que tinha a missão de anunciar esta nova ciência por todos os lados, mas escolheu a capital e algumas províncias do norte do Brasil como principal campo. Nestas também ocorreram discussões que envolveram as nacionalidades. Seguir sua vida trouxe muitas histórias e aqui se narrou apenas uma parte, entre tantas outras, de uma história de vida que foi interrompida precocemente, pois Martins faleceu em 7 de julho de 1854, ainda bastante jovem.

\section{Considerações finais}

A vida dos indivíduos é composta de relações sociais, de significações culturais e de sentidos históricos. Ao se aprofundar nas várias "camadas" das vivências, das memórias, das experiências que ficaram registradas e relatadas em alguma forma de linguagem ${ }^{70}$, nesse caso a escrita pela imprensa, os relatos da vida de João Vicente Martins exibiram um ser que se enquadrou num mundo que, em "contato com as pessoas, com as coisas, com as instituições, com as relações que coexistiram" expressou-se de maneira variada e os fragmentos de sua vida, aos quais tive acesso, fizeram surgir os elementos contraditórios que são constituidores da sua identidade. Uma identidade que apareceu como reflexo das experiências coletivas, mas também das escolhas que ele mesmo tomou e seguiu, e tudo logicamente situado dentro do contexto em que vivia.

A vida de Martins foi marcada por uma causa que ele abraçou e defendeu e, no sentido de suas escolhas, estava o significado de sua vida. Ele veio ao Brasil quiçá em busca de novas experiências, pois quem emigra o faz por algum objetivo, conforme diz Alves, “o 'horizonte mítico' é o grande operador da emigração, ao nível das decisões individuais e familiares, independentemente do posicionamento social à partida ou do desnível entre mito e realidade que se venha a verificar"72. Ao emigrar o indivíduo vai "ao encontro de aspirações construídas no confronto com o meio e representações sociais nele dominantes, apoiadas no exemplo de figuras reais e próximas"73. Logo, Martins, ao chegar ao Brasil, buscou se situar num espaço com o qual se identificava, acreditando que, ao se inserir na sociedade brasileira, poderia, além de usufruir dela, também contribuir para a nação em formação. Todavia, por sua fala, ele se apresentou como um indivíduo pouco satisfeito com a profissão que exercia e, por isso, tomou a decisão de percorrer outras cidades e se dedicar apenas à cirurgia dos olhos, considerada por ele como mais relevante porque lhe dava um maior sentido de vida.

Inicialmente, apresentou-se como estrangeiro, mas posteriormente, em sua autodefinição, ele assumiu um lugar que já não se enquadrava no ser estrangeiro: ele era português, e a definição de ser português tomou um corpo distinto dos demais estrangeiros, assumindo um lugar/status diferente na nação em formação.

\footnotetext{
${ }^{67}$ Idem.

${ }^{68}$ Ibidem, p. 3.

${ }^{69}$ Idem.

${ }^{70}$ ALBUQUERQUE Jr., Durval Muniz. A gente é cria de frases: sobre história e biografia. Maracan, Universidade Federal do Rio Grande do Norte, jan./dez. 2012. p. 23.

${ }^{71}$ Ibidem, p. 21.

${ }^{72}$ ALVES, Jorge Fernandes, 1993, Op. Cit., p. 188.

${ }^{73}$ Idem.
} 
Num dos discursos em que se apresentou como estrangeiro, ele disse que havia decidido renunciar à remuneração paga pelo Hospital dos Lázaros porque, na "qualidade de estrangeiro, reconheci que não devia exercer empregos públicos fora da minha pátria"74, e definiu a renúncia como uma atitude de respeito à nacionalidade brasileira. Já, noutro momento, ele disse que tinha como missão no Brasil reconquistar para sua querida pátria o amor de seus irmãos de aquém-mar ${ }^{75}$, logo, ser português assumia a categoria de "irmão". A origem étnica do Brasil, baseada nos laços de sangue que uniam portugueses e brasileiros por trezentos anos, era sempre referida por ele. Ao citar as prerrogativas dos filhos de estrangeiros nascidos no Brasil, que ao nascerem em terras brasileiras eram considerados naturalmente estrangeiros, e comparar com os direitos adquiridos pelos filhos de portugueses nascidos no Brasil, os quais eram logo denominados brasileiros, delineou e elevou o "ser português" para uma categoria diferenciada dos demais estrangeiros. Tornou-se então muito comum na defesa de Martins o uso do discurso do parentesco entre o brasileiro e o português, mas com a ressalva de ambos não comporem um mesmo povo. Emergia de sua fala ser o lugar por ele ocupado, merecedor de todo respeito e destaque, porque ele e todos os "bons" portugueses eram dignos do mesmo, afinal os brasileiros deviam "a sua grandeza mais que muito a sua origem, ao sangue português que nas suas veias [corria]" ${ }^{76}$

Martins aproximou, de certa forma, a definição do bom português a si próprio. Ao trazer para si o sentido do ser português, ao se autoapresentar como o modelo do bom português, Martins não somente foi criticado pelos nacionais, mas também por alguns de seus conterrâneos. Quando esteve em Pernambuco anunciou que se lá ficasse mais tempo denunciaria os maus portugueses, que eram aqueles "somente de nome", não possuidores do caráter português, desencadeando-lhe tal postura uma crítica ferrenha de um conterrâneo seu.

O jornal A Imprensa publicou um artigo direcionado ao Médico do Povo ${ }^{77}$ - jornal de propriedade de João Vicente Martins, dr. Sabino Olegario Ludgero Pinho e de dr. Alexandre José de Mello - o qual analisava o teor de uma reportagem publicada por este último, que narrava a história de Portugal "nas épocas gloriosas do seu passado, tocando no que de comum com o Brasil lhe pareceu conveniente"78. Uma das conclusões do artigo era que "as nacionalidades brasileira e portuguesa se acham confundidas" e essa confusão "das duas nacionalidades é o que se depreende sem nenhum esforço de querer o Médico do Povo que os portugueses que vivem no Brasil tenham como nós o mesmo direito". Orientava que as coisas deveriam tomar o seu devido lugar, pois,

é de mister que se convenção uma vez por todas os portugueses [de] que não são brasileiros, e os brasileiros de que não são cidadãos portugueses.

Neste nosso pedido não há nada de exagero. Depois que o Brasil se constituiu uma nação há duas nacionalidades distintas - brasileira e portuguesa: não há mais português d’aquém e portugueses d'além mar, não há nem pode haver; porque então o nome português devia desaparecer, e dir-se-hia brasileiros d'aquém, e brasileiros d'além mar

Nenhuma nação quer ver confundida com outra a sua nacionalidade ${ }^{79}$ (Grifos do autor).

O autor do artigo discordava da opinião que pregava o discurso da irmandade entre as nações brasileira e portuguesa, e reforçava que uma fronteira era necessária para a definição de ambas as

\footnotetext{
${ }^{74}$ Jornal do Commercio, Rio de Janeiro, n. 121, p. 3, 1 de maio de 1848, ano XXIII.

${ }^{75}$ MARTINS, João Vicente. Publicações a Pedido. Spontaneidades I. Correio Mercantil, Rio de Janeiro, no 114, p. 3, 27 de abril de 1849 , ano VI.

${ }^{76}$ MARTINS, João Vicente, Homeopatia - O cirurgião português João Vicente Martins ao público. Jornal do Commercio, Rio de Janeiro, n. 47, p. 2, 16 de fevereiro de 1846, ano XXI.

${ }_{77}$ O Médico do Povo foi criado primeiro na Bahia em 7 de setembro de 1850 e depois em Pernambuco em 2 de outubro do mesmo ano, de propriedade de João Vicente Martins, dr. Sabino Olegario Ludgero Pinho e dr. Alexandre José de Mello. Era um jornal que, apesar de ter a finalidade de divulgar a medicina homeopática, também se dedicava às questões de "interesses gerais humanitários, religiosos e científicos”, mas declarava que sempre que possível se afastaria das questões políticas.

${ }^{78}$ [Sem autor]. Ao Médico do Povo. A Imprensa, Recife, n. 33, p. 3, 10 de fevereiro de 1851, ano II.

${ }^{79}$ Idem. Recife, n. 33, p. 3, 12 de fevereiro de 1851, ano II.
} 
nacionalidades. Discordava assim do discurso que Martins defendia.

Mas, o interessante é que João Vicente Martins nunca negou ser português e, pelo contrário, sempre que podia afirmava a sua nacionalidade, apesar de, em 1853, se ter naturalizado brasileiro. $\mathrm{Na}$ análise deste debate foi possível compreender que a retórica adotada na defesa da presença dos portugueses no Brasil, quando situada na conjunção em estudo, deixou claro que Martins foi um grande articulador de ideias, um homem do seu tempo, que defendeu aquilo em que acreditava, e viu no discurso da irmandade um caminho para amainar os discursos antilusitanos, os quais se apresentavam como uma ameaça para a presença portuguesa no Brasil. A contextualização do seu discurso faz emergir os "elementos contraditórios que constituem a identidade de um indivíduo e das diferentes representações que dele se possa ter conforme os pontos de vista e as épocas" ${ }^{80}$.

\section{Referências bibliográficas}

\section{Fontes primárias}

Correio Mercantil, Instructivo, Político e Universal, Rio de Janeiro, n. 131, 13 mai. 1848; n. 107, 23 abr. 1849; n. 110, 23 abr. 1849; n. 114, 27 abr. 1849; n. 112. 2 mai. 1849; n. 139, 22 mai. 1849; n. 175, 29 jun. 1849.

Jornal do Commercio, Rio de Janeiro, n. 28, 6 fev. 1837; n. 225, 25 set. 1839, n; 47, 16 fev. 1846; n. 121, 1 mai. 1848; n. 87, 29 mar. 1850.

Folhinha Homeopatica do Brasil para o ano de 1846.

Revista Brasileira de Homeopatia, 1991.

O Grito Nacional, Rio de Janeiro, n. 60, 26 mai. 1849; n. 141, 23 mar. 1850.

O Brasil, Rio de Janeiro, 25 mai. 1849.

O Fuzil, Rio de Janeiro, n. 9, 4 set. 1849.

A Imprensa, Recife, 10 fev. 1851.

\section{Fontes secundárias}

ALBUQUERQUE Jr., Durval Muniz. A gente é cria de frases: sobre história e biografia. Maracan, Universidade Federal do Rio Grande do Norte, jan./dez. 2012. História: a arte de inventar o passado. Ensaios de teoria da história. Bauru, SP: Edusc, 2007.

ALVES, Jorge Fernandes. Os "brasileiros": emigração e retorno no Porto oitocentista. Porto: Universidade do Porto, 1993.

DETIENNE, Marcel. A identidade nacional, um enigma. Tradução de Fernando Scheibe. Belo Horizonte: Autêntica Editora, 2013; Terra, 1990 [e-book]. (Coleção História e Historiografia)

FOUCAULT, Michel. Cómo se ejerce el poder. Disponível em: http://www.unizar.es/deproyecto/programas/ docusocjur/FoucaultPoder.pdf.

GALHARDO, José Emígdio Rodrigues. Livro do $1^{\circ}$ Congresso Brasileiro de Homeopatia. Rio de Janeiro: Instituto Hahnemanniano do Brasil, 1928.

HOBSBAWM, Eric J. Nações e nacionalismo desde 1780: programa, mito e realidade. Rio de Janeiro: Paz e Terra, 1990.

KHALED Jr., Salah H. Horizontes identitários: a construção da narrativa nacional brasileira pela historiografia do século XIX. Porto Alegre: EdiPUCRS, 2010.

LESSER, Jeffrey. A negociação da identidade nacional: imigrantes, minorias e a luta pela etnicidade no Brasil. São Paulo: Unesp, 2001.

LEVI, Giovanni. Os usos da biografia. In: AMADO, Janaína; FERREIRA, Marieta de Moraes (org.). Usos e abusos da história oral. Rio de Janeiro: Editora da FGV, 1996. p. 167-182.

REIS, José Carlos. As identidades do Brasil 1: de Varnhagen a FHC. Rio de Janeiro: Editora FGV, 2017.

RENAN, Ernest. Que é uma nação? Tradução de Samuel Titãn Jr. Revista Plural, São Paulo, Sociologia, USP, vol. 4, n. 154-175, 1º semestre 1997.

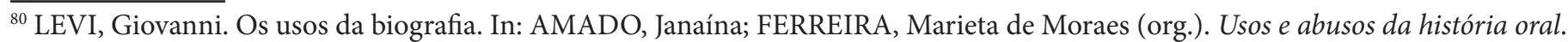
Rio de Janeiro: Editora da FGV, 1996. p. 167-182; 1996, p. 170. 
RIBEIRO, Gladys Sabina. A liberdade em construção: identidade nacional e conflito antilusitanos no Primeiro Reinado. Rio de Janeiro: Editora: Relume Dumará e Faperj, 2002.

RIBEIRO, Gladys Sabina; TERRA, Paulo Cruz;_POPINIGIS, Fabiane._Portugueses e cidadãos. Experiências e identidades nos séculos XIX e XX. Rio de Janeiro: Mauad X; Faperj, 2018.

ROWLAND, Robert. Manuéis e Joaquins: a cultura brasileira e os portugueses. Etnográfica, vol. V, n. 1, p. 157$172,2001$.

SANTOS, Wilza Betania dos. Gabinete Português de Leitura de Pernambuco: (re)significação duma identidade portuguesa. 2013. 123 p. Dissertação (Mestrado), História Contemporânea, Faculdade de Letras da Universidade do Porto, Flup, Porto, Portugal, 2013.

Caminhos identitários: imigrantes portugueses em Pernambuco. Revista de História, São Paulo, n. 177, p. 01-33, maio de 2018. ISSN 2316-9141. Disponível em: <https://www.revistas.usp.br/revhistoria/ article/view/126642>. DOI: http://dx.doi.org/10.11606/issn.2316-9141.rh.2018.126642.

SOBRAL, José Manuel. Portugal, portugueses: uma identidade nacional. Lisboa: Fundação Francisco Manuel dos Santos e José Manuel Sobral, 2016 [e-book].

Recebido em: 06/11/2017 - Aprovado em: 04/07/2018 